\title{
Metamorfoses da Ordem Urhana da Metrópole Brasileira: o caso do Rio de Janeiro
}

LUIZ GESAR DE QUEEROZ RIBEIRO*

\section{Resumo}

Este artigo utiliza como base as teses propostas no livro "Rio de Janeiro: Transformações na Ordem Urbana" para formular uma síntese interpretativa que elucide as mudanças ocorridas na metrópole do Rio de Janeiro no período compreendido entre 1980 e 2010. Para tal, retomam-se alguns elementos históricos, teórico-metodológicos e analíticos que funcionaram como referências contextuais e pontos de partida para a consolidação da obra e desta síntese. Um desses elementos é a construção do conceito de ordem urbana e como este se expressa na organização do território da metrópole do Rio de Janeiro. Mostra-se que resultam das relações específicas de poder social, econômico e político que sustentam sua ordem urbana padrões de segregação baseados na "distância social/proximidade territorial, distância social/distância territorial" entremeados pela manutenção da escassez urbana e relativa.

Palavras-chave: Ordem Urbana. Organização Social do Território. Metropolização. Segregação. Rio de Janeiro.

\footnotetext{
* Universidade Federal do Rio de Janeiro (Brasil)
} 


\section{Metamorphoses of the Urban Order of Brazilian Metropolis: the case of Rio de Janeiro}

\section{Abstract}

This article is based on the thesis proposed in the book "Rio de Janeiro: Transformações na Ordem Urbana" in order to formulate an interpretative synthesis that will clarify the changes evidenced in the metropolis of Rio de Janeiro between 1980-2010's. For this purpose, we retake the historical, theoretical-methodological and analytical elements that were used as contextual references and starting points for the aforementioned work consolidation. One of these elements is the conception of urban order and how it is expressed on the territorial organization of Rio de Janeiro metropolitan area. It is shown that patterns of segregation based in the "social distance/territorial proximity, social distance/territorial distance" result from specific relations of social, economic and political power implicated by the maintenance of urban and relative scarcity.

Keywords: Urban Order. Social Territorial Organization. Metropolization. Segregation. Rio de Janeiro.

Métamorphoses, dialectique du même et du diferent; dégager les transformations historiques de ce modèle, souligner ce que ses príncipales cristallisations comportent à la fois de nouveau et de permanent, fût-ce sous des formes qui ne les pas immediatement reconnaissables.(Castel, 1995, p.16) 


\section{Introdução}

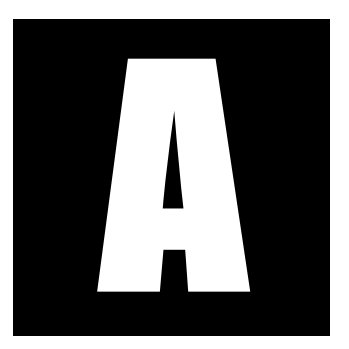

epígrafe deste texto contém a essência da nossa síntese sobre a trajetória da metrópole do Rio de Janeiro nos últimos 30 anos. Contrariamente ao senso comum ordinário e mesmo erudito - que embalado por metáforas retumbantes negativas e positivas (tais como cidade partida ou cidade olímpica) vem buscando marcar rupturas e descontinuidades na ordem urbana em função de sucessivos ciclos de crise e de crescimento - cabe dizer que o Rio de Janeiro do século XXI continua o mesmo. Uma cidade-metrópole que reproduz em seu interior o modelo urbano desigual constituído quando da sua incorporação na segunda onda da modernização periférica nacional iniciada nos anos 1930. Modelo urbano simultaneamente produtor e reprodutor de relações sociais de dominação e de lutas cujo epicentro é a apropriação do território como base de acesso seletivo aos recursos urbanos escassos, sejam eles materiais ou simbólicos. Mas se esta substância da ordem urbana do Rio de Janeiro tende a manter-se, por outro lado, observamos tendências à emergência de novas formas pelas quais ela se expressa.

O presente artigo se constitui como uma crônica da evolução histórica da metamorfose da ordem urbana no período 1980-2010, conforme a dialética do mesmo e do diferente. Ele tem como base a síntese de pesquisa realizada pelo Observatório das Metrópoles entre 2009-2015 sobre as mudanças da ordem urbana na metrópole do Rio de Janeiro, como parte do programa de investigação intitulado "Metrópoles: coesão social, território e governança" que em seu escopo realizou um trabalho comparativo entre 14 diferentes contextos metropolitanos brasileiros ${ }^{1}$. Como

\footnotetext{
${ }^{1} \mathrm{O}$ conjunto dos resultados deste programa foi traduzido na coleção Metrópoles: transformações urbanas, disponível em < http://transformacoes.observatoriodasmetropoles.net>.
} 
base para nossa discussão partimos das seguintes indagações: quais os impactos na metrópole fluminense das mudanças econômicas e políticas ocorridas no Brasil nos últimos 30 anos? Podemos identificar sinais de transformações na ordem urbana? Qual a pertinência de tomar como referência em nossa análise o período compreendido entre 1980 e 2010 ?

O texto está divido em seis partes. Após esta introdução, a segunda parte apresenta de maneira sumária a formulação do conceito de ordem urbana que norteou a nossa análise. Por ele, buscamos analisar a articulação da organização social do território com os mecanismos de produção e reprodução das relações sociais. Na terceira parte, descrevemos os traços gerais dessa ordem urbana no Brasil como integrante das condições que presidiram as transformações sociais da sociedade brasileira na fase da industrialização acelerada iniciada nos anos 1940. $\mathrm{Na}$ quarta parte, apresentamos como esses traços gerais se traduziram na metrópole fluminense em uma ordem urbana na qual as relações de classe vão se expressando em um padrão segregado e desigual de organização social expresso em uma dupla gramática social ${ }^{2}$ de distanciamento, hierarquia e desigualdade. Na quinta parte, sintetizamos a análise empírica das transformações de várias dimensões da ordem urbana ocorridas na Região Metropolitana do Rio de Janeiro no período a partir de 1980. Por fim, concluímos refletindo sobre os mecanismos explicativos da reprodução desta ordem urbana, não obstante o período analisado comportar diferentes conjunturas econômicas e políticas.

\footnotetext{
${ }^{2} \mathrm{O}$ emprego do termo gramática deve-se a nossa intenção de destacar a necessidade de ultrapassar a leitura puramente espacial da segregação residencial, compreendendo os significados sociais possíveis presentes das interações proporcionadas pelo distanciamento e proximidade realizados através do território. Ao nosso ver, isto somente é possível lendo a segregação residencial com a partir do reconhecimento dos padrões institucionalizados que naturalizam e legitimam as hierarquias e as desigualdades da sociedade. Tal propósito tem afinidade com os trabaIhos de Katzman (2007) sobre a compreensão dos padrões de segregação residencial na América Latina, de Souza (2004) sobre os fundamentos das desigualdades sociais no Brasil e de Nunes (1997) e Nunes (1997) sobre os padrões de relações políticas entre Estado e Sociedade no Brasil.
} 


\section{A ordem urbana: construção de um conceito}

O que queremos enunciar com a expressão "ordem urbana" adotada como chave em nossa análise? Trata-se de pensar a organização social do território como uma das instâncias da sociedade, portanto, expressando ordens material, institucional e simbólica. Esta concepção teórico-metodológica tem como ponto de partida referências clássicas da sociologia urbana sobre a incontornável necessidade teórica de pensar a cidade a partir da relação entre sociedade e espaço. Dentre eles cabe destacar o trabalho seminal de Castells (1975), no qual o autor coloca que a compreensão do fenômeno urbano somente torna-se possível entendendo a cidade como projeção da sociedade, ou seja, tomando a relação entre a cidade e a sociedade como fatos sócio-históricos e morfológicos.

Este ponto de partida é o único que permite superar o empirismo da descrição da cidade como um objeto geográfico ou demográfico singular, tarefa fundamental especialmente em um projeto de pesquisa orientado por preocupações comparativas sobre as mudanças socioespaciais. Mas, como já advertia Castells, a busca em superar o empirismo abre o risco de considerar o espaço como uma folha em branco na qual se inscreve a ação dos grupos sociais e das instituições, sem encontrar outro obstáculo senão o das gerações passadas (Castels, 1972, p. 181). Mais adiante, o autor em seu célebre texto, afirma que a forma, a função e a significação do espaço constituído como cidade não pode ser apreendido como uma pura ocasião de desdobramento da estrutura social, mas a expressão concreta de cada conjunto histórico, no qual uma sociedade se específica (Castells, 1975, 152). Trata-se então de estabelecer, da mesma maneira que para qualquer outro objeto real, as leis estruturais e conjunturais que comandam sua existência e sua transformação, bem como a especificidade de sua articulação com os outros elementos de uma realidade histórica. Castells então conclui que: não há uma teoria do espaço que não seja parte integrante de uma teoria social geral, mesmo que ainda implícita (Castells, 1975, p. 152). 
Reconhecemos que retomar essas considerações teóricas atualmente pode parecer ingênuo diante da evolução e complexificação hoje alcançadas pelo "pensamento urbano", em especial em função das pesquisas inspiradas nas formulações de Henry Lefebvre e de David Harvey. Mas consideramos importante recuperar essas ideias de Castells para explorar duas implicações importantes para o nosso objetivo. A primeira - com um caráter mais epistemológico e teórico - seria de: (i) reafirmar a necessidade da construção teórica do nosso objeto de análise comparativa (a ordem urbana), superando a atitude intuitiva e empírica; (ii) compreendendo-a como resultante de uma relação entre uma sociedade concreta; (iii) por sua vez compreendida como uma realidade espaço-temporal específica; (iv) compreensão esta somente possível em função da adoção de uma teoria social.

Gostaríamos de destacar este último aspecto, na medida em que ele contribui para nos situarmos no universo do pensamento urbano. Sabemos que não existe uma teoria social, mas várias teorias sociais possíveis por meio das quais podemos compreender uma sociedade concreta. Com efeito, o vasto campo disciplinar das ciências sociais é fortemente marcado pela existência de várias possibilidades distintas de formulação teórica, que se distinguem pelas orientações epistemológicas, teóricas e metodológicas de suas propostas de objeto sociológico a ser explicado e pelos fundamentos da sua explicação. Nos inúmeros compêndios e manuais existentes sobre teoria urbana, encontramos distintas maneiras de apresentar esta diversidade, dependendo da própria filiação do autor: individualismo-metodológico, coletivismo-metodológico e individualismo teórico; ou estruturalismo, historicismo e culturalismo.

Muitas vezes, essas teorias sociais estão implícitas nas formulações teóricas da relação entre sociedade e espaço ou sociedade e cidade. A nossa apropriação das proposições e hipóteses dessas teorias deve ser, 
portanto, consciente das suas orientações e fundamentos. Não apenas em razão da adesão pelas nossas afinidades eletivas em termos de escolha valorativa historicamente expressiva, como diria Max Weber, mas também pelas afinidades eletivas com o nosso problema de pesquisa.

A segunda implicação é de caráter analítico e metodológico. Assumir como ponto de partida que a cidade resulta de uma relação biunívoca entre a sociedade e o espaço implica assumir que o espaço urbano é estruturado. Ou seja, quer dizer que ele não está organizado ao acaso, e os processos sociais que se ligam a ele exprimem, ao especificá-los, os determinismos de cada tipo e de cada período da organização social (Castells, 1972 , p. 162). Portanto para entender a ordem urbana é preciso passar necessariamente pela compreensão dos efeitos específicos dos processos sociais na organização do território.

Coerente com o enunciado acima, propomos a construção do conceito de ordem urbana a partir da teoria da social crítica que postula a compreensão da organização social como uma totalidade fundada nas relações de poder entre grupos e classes sociais. Essas relações de poder têm múltiplas expressões concretas na sociedade, sendo comumente identificadas as relativas às esferas econômica, social e política. Mas, considerando as teorizações de Bourdieu, tais esferas traduzem formas distintas de estruturação e de exercício de poder resultantes da complexificação e diversificação interna da sociedade, o que em sua teoria são enunciadas através do conceito de campo. O surgimento dos campos de estruturação e exercício do poder tem fundamento nas lutas sociais entre classes e frações de sociais em torno da dominação (Bourdieu, 1979). 


\section{A ordem urbana brasileira: contexto histórico}

Por que tomar como referência em nossa análise o período histórico mencionado? Deve-se, sobretudo, à compreensão de que nessas décadas sucederam três marcantes períodos históricos em função da emergência de tendências de transformação da sociedade brasileira no plano da economia, da sociedade e do Estado, ainda que todas contenham dinâmicas ambíguas e mesmo contraditórias. O primeiro período correspondente aos anos 1980, considerado como a "década perdida" pelo baixo crescimento econômico, aumento das desigualdades sociais, do desemprego e subemprego, da pobreza urbana, da explosão da criminalidade violenta, enfim, da crise social resultante do esgotamento do modelo de industrialização. Mas, ao mesmo tempo, foi o momento de redemocratização, com a retomada dos movimentos sindicais e sociais e dos governos estaduais e municipais progressistas, além da elaboração da Constituição de 1988 enquanto marco institucional da construção de contrato social fundado em princípios e instrumentos de um regime de bem-estar social.

Em 1991 inicia-se um novo período marcado pelas políticas que buscavam a estabilização monetária, pela economia nacional voltada à competição global e, sobretudo, pelo "experimento neoliberal" introduzido na segunda metade dos anos 1990. A estabilização da moeda é alcançada e são gerados significativos efeitos positivos na estrutura das desigualdades da renda pessoal, ao mesmo tempo em que a reestruturação produtiva das empresas e do setor público via privatização - aliada às sucessivas crises cambiais - produziu impactos negativos no mercado de trabalho.

O terceiro período tem como marco a eleição de Luiz Inácio Lula da Silva, mas toma forma a partir de 2005 quando várias iniciativas do Governo vão constituindo um "experimento neodesenvolvimentista", viabilizado pela retomada do crescimento econômico mundial alavancado pela expansão da industrialização da China. A combinação de políticas 
sociais com o crescimento da renda e do emprego criou um dinamismo de crescimento econômico com distribuição da renda, expansão do crédito e da incorporação ao mercado de bens de consumo duráveis de amplas camadas populares historicamente, até então, dele excluídas. $\mathrm{O}$ setor público se expande e o Estado retoma o seu papel de provedor de bens essenciais, a exemplo da habitação de interesse social.

Tendo esses cenários históricos como referência, pareceu-nos pertinente indagar se no período dos últimos 30 anos encontramos sinais de uma inflexão urbana nas metrópoles brasileiras ${ }^{3}$. A pertinência dessa pergunta funda-se na compreensão de que as características da metropolização brasileira decorreram das condições econômicas, sociais e políticas que presidiram a nossa industrialização acelerada a partir da segunda metade dos anos 1950 sob a hegemonia do capitalismo monopolista, vale dizer, do complexo industrial-financeiro ${ }^{4}$. Como aponta Arend (2012), a nossa industrialização ocorreu em dois momentos distintos que se diferenciam em função das condições sistêmicas que delimitaram a nossa inserção na economia-mundo capitalista.

Entre 1930-1951 prevaleceu a estratégia nacional-desenvolvimentista de Getúlio Vargas, na qual as grandes empresas internacionais eram convocadas para desenvolver os setores relacionados com a infraestrutura econômica e os capitais nacionais dos setores de bens de consumo. Essa estratégia é enfraquecida já no segundo governo de Vargas devido a mudanças das condições sistêmicas globais de acumulação, entre elas a consolidação da hegemonia dos Estados Unidos da América e a sua escolha geopolítica pela

\footnotetext{
${ }^{3}$ A hipótese da inflexão da ordem urbana foi analiticamente construída e apresentada em Ribeiro (2013).

${ }^{4}$ Como afirmou Fernandes, a nossa inserção na expansão do capitalismo industrial-financeiro faz surgir a hegemonia urbana e metropolitana simultaneamente no território nacional, da qual decorre uma dinâmica de concentração de recursos materiais, humanos e técnicos em algumas cidades, dando origem a fenômenos típicos de metropolização e de satelização sob o capitalismo dependente (Fernandes, 1976, p. 207).
} 
Europa e Japão. O governo estadunidense pressiona o governo brasileiro a abrir para as grandes empresas americanas os setores de produção de bens duráveis. A eleição de Juscelino Kubitschek e o seu Plano de Metas expressam uma transformação do bloco de poder interno e a mudança da estratégia na direção de um desenvolvimentismo associado (1950-1980) às grandes empresas internacionais produtoras dos bens duráveis, setor que ocupava o núcleo da acumulação capitalista mundial naquele momento.

A metropolização gerada pela expansão industrial sob a hegemonia monopolista também se expressou pela constituição de ordem urbana condizente com a forte concentração do poder econômico, social, político e cultural das classes possuidoras da renda, riqueza e oportunidades e do vasto e heterogêneo mundo do trabalho constituído pela mobilização da força de trabalho realizada mediante intensiva migração campo-cidade. Nas cidades de São Paulo e Rio de Janeiro os fluxos migratórios atingiram até 1970 cerca de 30 milhões de pessoas frente a uma população que era de 93 milhões. Portanto, a urbanização acelerada foi o mecanismo central da constituição do exército industrial de reserva do qual se originam os traços fundamentais do capitalismo industrial brasileiro (Singer, 1975). Esse seria o fundamento histórico do crescimento urbano que se organiza à semelhança dessa lógica que é característica da expansão das fronteiras das relações capitalistas. A dinâmica de ocupação do território metropolitano das duas maiores cidades do país reproduziu no espaço urbano os mesmos mecanismos de gestão da conflitualidade social do capitalismo industrial periférico que se constituiu no Brasil (Fiori, 1995; Tavares, 1999), cuja marca principal foi a combinação entre autoritarismo e laissez-faire na regulação das relações sociais ${ }^{5}$. A intensidade e

\footnotetext{
${ }^{5}$ Vale a pena nessa reflexão considerar a seguinte descrição de Tavares sobre os fundamentos territoriais e demográficos da aliança conservadora que presidiu o desenvolvimento do capitalismo brasileiro: O recurso periódico a uma ordem autoritária busca suas razões de Estado tanto na preservação do território nacional quanto no apoio à expansão capitalista, em novas frontei-
} 
a velocidade do processo de mobilização da força de trabalho por meio da migração das massas rurais geraram uma metropolização precoce e explosiva $^{6}$, constituindo um espaço urbano cuja marca é a produção de áreas precárias e improvisadas em termos de urbanização e acesso a bens e serviços básicos. Áreas que cumpririam o papel de fronteira interna ao espaço de reprodução do capital por nelas se acumularem reservas de força de trabalho e de ativos para futuros ciclos de expansão capitalista. É por essa razão que podemos explicar a aparente contradição do capitalismo industrial brasileiro ao concentrar a propriedade privada da terra no campo e difundi-la na cidade por meio de mecanismos que combinaram preços e instituições sociais locais fundadas na convenções e valores compartilhados pela população ${ }^{7}$. Em suma, a mobilização da força de trabaIho via migração-metropolização implicou na constituição de uma ordem urbana desigual e combinada, na qual se articulam relações e práticas e relações sociais próprias da uso e produção capitalista do espaço com

ras de acumulação, onde lhe cabia impedir a luta de classes aberta, dos senhores da terra e do capital entre si, e garantir a submissão das populações locais ou emigradas, que se espraiaram pelo vasto território brasileiro (...). Por sua vez, o processo de deslocamentos espaciais maciços das migrações rural-urbanas das nossas populações e as mudanças radicais das condições de vida e de exploração da mão-de-obra não permitiram, até hoje, a formação de classes sociais mais homogêneas, capazes de um enfrentamento sistemático que pudesse levar a uma ordem burguesa sistemática (Tavares, 1999, p. 457).

${ }^{6} \mathrm{O}$ conceito de metropolização aqui utilizado refere-se simultaneamente à concentração demográfica e produtiva nas três principais aglomerações - São Paulo, Rio de Janeiro e posteriormente Belo Horizonte - criando uma rede urbana polarizada. Ver a este respeito Ribeiro, Silva e Rodrigues (2011) e Lipetz (1989)

${ }^{7}$ A literatura clássica sobre a migração campo/cidade no Brasil descreveu este processo como um processo social no qual os laços sociais mantidos no ponto de origem estão presentes no ponto de chegada criando territórios urbanos que apesar da precariedade e pobreza eram mais que mais que a aglomeração de indivíduos. Singer, por exemplo, assinala em seu conhecido estudo sobre o tema: $A$ adaptação do migrante recém-chegado ao meio social se dá frequentemente mediante mecanismos de ajuda mútua e de solidariedade de migrantes mais antigos (Singer, 1975, p.55). 
outras típicas da criação, destruição e recriação de sucessivas fronteiras internas de reprodução do capital.

Mas, por outro lado, a ordem urbana que presidiu a metropolização também resultou do papel exercido pela acumulação urbana na viabilização da constituição de um bloco de poder fundado na aliança entre Estado, capital nacional e empresas internacionais, fato político conceituado como Sagrada Aliança ${ }^{8}$ por Lessa e Dain (1984). Para os autores, o Estado teria sido o fiel da aliança ao garantir duas cláusulas: a primeira, reservando aos capitais nacionais certos circuitos de acumulação não industriais como reserva; a segunda, estabelecendo formas de garantir uma partição horizontal da massa de lucros entre as duas órbitas, nivelando a rentabilidade. Os circuitos de valorização organizados pelos capitais imobiliário, empreiteiro de obras públicas, concessionários de serviços urbanos e pela propriedade da terra, integraram a órbita protegida e constituíram o segmento urbano da acumulação de capital, fato que está na base da histórica hipertrofia do papel da especulação na dinâmica da organização social do território em nossas metrópoles.

\section{A formação da ordem urbana da metrópole do Rio de Janeiro}

Podemos supor que no período 1980-2010 tenham emergido tendências de inflexões da ordem urbana construída nas metrópoles brasileiras? Esta hipótese coloca-se de maneira ainda mais pertinente no Rio de

\footnotetext{
${ }^{8}$ Lessa e Dain assim definiram a sagrada aliança: (...) uma comunidade e uma convergência de interesses entre capitais dominantes em órbitas de capital não-industrial e um sistema de filiais no circuito industrial. As relações são sistemáticas de solidariedade na expansão conjunta dos capitais existentes naquele espaço nacional de acumulação e que respeita uma "especialização", uma espécie de divisão do espaço, segundo órbitas, por capitais de diferentes procedências. Esse pacto se constitui com a presença do Estado (Lessa; Dain, 1984, p. 254).
} 
Janeiro em razão da sua trajetória na industrialização anterior, marcada pela perda precoce do seu dinamismo para São Paulo. Hoje com cerca de 12 milhões de habitantes, a metrópole fluminense acumula os efeitos de um intenso processo de uma urbanização dissociada da constituição de uma base industrial correspondente ${ }^{9}$, ou seja, uma base com capacidade de gerar um mercado de trabalho capaz de sustentar o grau de metropolização alcançado. Por outro lado, a "década perdida" dos anos 1980 produziu efeitos desproporcionais no Rio de Janeiro, manifestados na forma de uma crise social (desemprego, informalização, pobreza, violência, etc.) e urbano-metropolitana (crise habitacional, mobilidade urbana, crescimento das favelas, entre outros). Curiosamente, no entanto, nesse período de crises surgiu um intenso movimento de especulação imobiliária com a incorporação da grande área da Barra da Tijuca como nova frente de expansão urbana, fato que terá duradouros impactos na dinâmica de metropolização. Essa vasta área com mais de 105 quilômetros quadrados permaneceu à margem da expansão urbana da metrópole até a década de 1970. Ao final dos anos 1960, as terras da Barra estão nas mãos de quatro grandes proprietários: as empresas Esta, o Grupo de Desenvolvimento, a Carvalho Hosken S.A. e a Pasquale Mauro. Em 1970, o Grupo Desenvolvimento tenta realizar uma grande operação com o lançamento de um conjunto de torres, não conseguindo, porém, levá-lo a cabo. Após o fracasso do empreendimento, a empresa passa a vender várias glebas para as empresas Carvalho Hosken, Construtora Santa Izabel, ENCOL e Construtora Eldorado.

No início da década de 1970, no governo Negrão Lima, é realizado um conjunto de obras viárias, cuja finalidade foi promover a ligação da área com a zona sul da cidade. Posteriormente, é elaborado o Plano Lúcio

\footnotetext{
${ }^{9}$ Uma das razões do baixo dinamismo industrial do Rio de Janeiro decorre do forte peso em sua estrutura dos setores que se tornaram obsoletos nas sucessivas revoluções tecnológicas, como identificou Dain (1990). O célebre debate sobre o esvaziamento econômico do Rio de Janeiro foi enriquecido pelas recentes pesquisas de Silva (2012) e Sobral (2013).
} 
Costa que visava não apenas regular a ocupação do solo da Barra da Tijuca, mas também criar o "Rio de Janeiro do futuro". Em 1976, é editado o decreto no 324 que estabelece normas de construção específicas para a Barra e institucionaliza o Plano Lúcio Costa.

Ao final da década de 1970, a Barra está preparada para ser constituída como nova frente de expansão, comandada por uma coalização de interesses formada pelos quatro grandes proprietários de terra, algumas poucas grandes incorporadoras imobiliárias, grandes empresas de obras públicas e o poder público, configurando um caso típico de urbanização organizada pela lógica da geração e extração de um tipo de renda da terra semelhante à class-monopoly rent conceituada por Harvey (1974). Tal fato desencadeou uma força de arrasto na dinâmica de organização social do território metropolitano expresso no fato de a Barra da Tijuca passar a concentrar em 1989 mais da metade dos lançamentos imobiliários na cidade - medidos em metros quadrados - quando em 1980 eram apenas de 7,9\% (Ribeiro, 1997).

Aplicamos a análise socioespacial descrita no item anterior para os anos de 1980, 1991, 2000 e 2010 - a partir dos dados dos censos demográficos - e tendo como referência a descrição da metrópole nos anos 1970 que está consagrada em trabalhos que se tornaram clássicos no pensamento urbano sobre o Rio de Janeiro. Os textos de Vetter (1975), Santos e Bronstein (1978), Vetter et alli (1981), Vetter (1981) e Abreu (1987) apontam que a organização social do território metropolitano fluminense naquele momento, estava caracterizada por uma estrutura urbana dualizada núcleo-periferia ${ }^{10}$ que expressava as desigualdades de classe da

\footnotetext{
${ }^{10}$ Nesses trabalhos, a morfologia do território metropolitano era assim descrita: núcleo: área central comercial e financeira - antigo core histórico - e por sua expansão em direção à orla oceânica (a "Zona Sul") e ao interior (bairros da Tijuca, Vila Isabel, São Cristóvão e Caju) mais o Centro e a Zona Sul de Niterói; periferia próxima: subúrbios do eixo Madureira da linha Central do Brasil e do eixo Irajá da antiga Leopoldina, mais a Zona Norte de Niterói. Classicamente se inclui a Barra da Tijuca nesse espaço; periferia intermediária: Baixada Fluminense, parte de Magé e São Gonçalo; periferia distante: segundo os termos da época, seria a área conurbada.
} 
sociedade, apesar da significativa presença de áreas populares - como as favelas - no núcleo. Entendia-se que a política de remoção da população residente nessas áreas para a periferia representava a consolidação do padrão dualizado. Esses trabalhos - que compreendiam a reprodução das desigualdades regionais a partir das teorizações de Myrdal (1968) sobre a causação circular cumulativa e das desigualdades urbanas a partir dos conceitos de Harvey (1973) - buscavam explicar as forças que atuam na reprodução da estrutura núcleo-periferia da metrópole do Rio de Janeiro, destacando os impactos econômicos e políticos da dinâmica socioterritorial uma vez iniciado o processo de segregação residencial. Por um lado, as áreas com elevada concentração dos grupos que ocupam as posições mais elevadas da estrutura social constituem também um poder econômico e político que tende a influenciar a favor destes as decisões públicas em matéria de alocação de investimentos, se apropriando da maior parcela dos benefícios decorrentes, em termos de bem-estar urbano e oportunidades sociais. Ao mesmo tempo, esses grupos tendem também a ser beneficiados em termos de riqueza patrimonial, uma vez que a alocação seletiva dos investimentos urbanos produz impactos diferenciais na valorização da moradia e do solo urbano. Tendencialmente, na medida em que essa dimensão da desigualdade social é objeto de disputa pela apropriação da renda da terra, ela envolve os vários segmentos de atores presentes no mercado imobiliário em que se destacam os proprietários da terra, os incorporadores imobiliários e os próprios grupos segregados. O resultado dessa disputa é a elevação do preço da moradia e da terra nas áreas segregadas e privilegiadas pelos investimentos urbanos, o que leva ao deslocamento para fora desses espaços dos grupos sociais que ocupam posições inferiores da estrutura social e que, portanto, desfrutam de menor poder econômico e político, acentuando e reproduzindo a segregação. Portanto, o mecanismo da causação circular cumulativa reproduz o espaço desigual expresso na morfologia núcleo-periferia na medida em 
que as desigualdades do poder econômico e político se traduzem na segregação territorial deste poder que, uma vez constituído, transforma-se em poder de segregação, isto é, em capacidade de atuar seletivamente no acesso aos investimentos urbanos e aos espaços privilegiados.

Vejamos agora alguns elementos analíticos que resultaram em pontos de partida das análises empreendidas para responder as perguntas enunciadas no introdução deste texto. Em trabalhos anteriores (Ribeiro, 1986; Lago e Ribeiro, 1995; Ribeiro, 1997; Ribeiro e Lago, 2000; Ribeiro, 2000), buscamos interpretar as mudanças dos padrões e das dinâmicas da organização núcleo-periferia da metrópole fluminense no período 1980-2000 à luz deste marco analítico. Neles ampliamos, porém, a compreensão das forças socioterritoriais presentes na causação circular cumulativa da reprodução do padrão núcleo-periferia. Em primeiro lugar teríamos as forças decorrentes da economia política da urbanização do Rio de Janeiro, cuja marca central é o poder dos interesses configurados historicamente em torno da acumulação urbana, na qual têm fundamental peso político os interesses das frações do capital imobiliário tanto empreiteiro quanto concessionário de serviços coletivos. A ação desse poder comandou, por meio da intervenção do Estado, os sucessivos ciclos de expansão da cidade fundados na produção de novas centralidades e de novas frentes de expansão que foram configurando as características da dinâmica de organização do território da metrópole. O primeiro ciclo foi o da reconquista do centro da cidade do Rio de Janeiro em relação às classes populares - no período marcado pelas reformas urbanas realizadas por Pereira Passos - quando as classes dominantes pretendiam realizar a construção de uma Paris nos Trópicos. O segundo corresponde ao momento da apropriação de Copacabana e a invenção da "Zona Sul - Edifício de Apartamentos" nos anos 1930-1980, nova centralidade apresentada como a construção de um Paraíso Tropical por prometer a junção da natureza com a modernidade. O terceiro grande ciclo inicia-se 
já no final dos anos 1970 e perdura até este momento com a apropriação e invenção da "Barra da Tijuca - Condomínio Fechado" como nova centralidade, a qual corresponde à edificação da Miami da América Latina enquanto promessa de um modelo urbano pós-moderno ${ }^{11}$. Cada um desses ciclos resulta da ação de coalizões políticas dos interesses presentes na acumulação urbana e sua capacidade de orquestrar a intervenção pública como base da constituição de sucessivas centralidades ${ }^{12}$.

A segunda força impulsionadora do mecanismo da causação circular cumulativa foi decorrente da irrupção na estrutura social de uma nova classe média profissional também conhecida como a "alta classe média ${ }^{13 "}$, ligada ao processo de industrialização do país ${ }^{14}$. Algo que ocor-

\footnotetext{
${ }^{11}$ Utilizamos como marcadores simbólicos de cada ciclo as criativas e pertinentes metáforas construídas por Lessa (2000) para simbolizar a natureza do processo de desenvolvimento urbano do Rio de Janeiro no século XX.

${ }^{12}$ Vivemos no presente momento a emergência de um novo ciclo da acumulação urbana fundado na reconquista da antiga área central da cidade do Rio de Janeiro, conforme pode descrito por Brito (2015).

${ }^{13} \mathrm{O}$ conceito de Nova Classe Média Profissional aqui mencionado é utilizado de forma semeIhante ao formulado por Goldthorpe (1980) na categoria Higher-Grade Professionals e por Boltanski (1982) na categoria Cadre. De forma resumida cabe dizer que se trata de um grupo relativamente heterogêneo em termos de sua atuação profissional, mas coeso no que tange à posição ocupada no espaço social. Além de sua formação escolar elevada ele se caracteriza por exercer funções executivas de comando principalmente no setor privado, mas também no público.

${ }^{14}$ É a compreensão desse fato que dá sentido à famosa frase de Francisco de Oliveira, em texto escrito em 1982 quando o urbano começava a despontar como questão política sob o impulso dos movimentos pela redemocratização: Eu resumiria, afirmando que o urbano é hoje no Brasil as classes médias, isto é, as cidades são por excelência - recuperando a questão da terceirização - sob esse ângulo - a expressão urbana dessa nova classe, onde o peso das classes médias emerge com enorme força, com enorme gravitação, tendo em vista o tipo de organização que o capitalismo internacional criou ao projetar suas empresas dentro da sociedade brasileira. Isso também tem importância do ponto de vista político. A enorme gravitação das classes médias no Brasil, vista sob outro aspecto, é uma das bases do autoritarismo da sociedade brasileira. Do ponto de vista do urbano, das relações entre o Estado e o urbano, essas classes médias criaram demandas dentro das cidades. E o Estado hoje, do ponto de vista de sua relação com o urbano, entre outros aspectos importantes, saliento, é em grande maioria determinado pela demanda das classes médias dentro da cidade (Oliveira, 1982, p. 25).
} 
reu especialmente após os anos 1950, com a modernização do Estado e a instalação no Brasil de grandes empresas internacionais. Cabe ressaltar que na sociedade brasileira não se conforma apenas um grupo social semelhante àquele identificado por Charles Wright Mills como os white collar. Mas sim uma classe social, que apesar de pouco numérica, gerou uma força gravitacional na política urbana com base em sua coesão social e na fragmentação do mundo popular urbano como consequência da existência do já citado vasto exército industrial de reserva na metrópole. Ou seja, a concentração territorial desse grupo coeso, realizada abruptamente em razão da força da acumulação urbana que foi desbravando novas frentes de expansão urbana e criando novas centralidades, intensificou e acelerou na dinâmica socioterritorial da metrópole a transformação da segregação do poder em poder de segregação.

Em terceiro lugar, integramos, em nossa maneira de conceber as dinâmicas de organização social do território metropolitano do Rio de Janeiro, a dimensão dos conflitos sociais em torno da apropriação do território metropolitano como base do acesso seletivo às fontes de bem-estar, oportunidades e riqueza patrimonial. Com efeito, em nossa concepção, a vigência do mecanismo de causação circular cumulativa desde os anos 1970 já continha contra tendências à concretização do padrão desigual centro-periferia, o que nos leva a superar a concepção dualista subjacente às análises anteriores. Nos nossos trabalhos mencionados anteriormente - e também em outros - constatamos a ação de três dinâmicas: a auto-segregação das classes superiores na forma da sua forte concentração nos espaços mais valorizados, a periferização das classes populares, além da infiltração em áreas do núcleo metropolitano e de sua periferia imediata por parte dessas mesmas camadas populares, processo conhecido no senso comum como "favelização". 
Tal interpretação funda-se em nossa compreensão do caráter desigual e combinado da formação da ordem urbana das metrópoles brasileiras, conforme enunciado anteriormente. Contudo algumas precisões são necessárias. Não utilizamos conceito de infiltração no sentido ecológico-funcionalista por Mckenzie (1970), mas como resultado das lutas sociais em torno do solo urbano como fundamento do acesso aos recursos que incidem sobre o bem-estar, patrimônio imobiliário, renda monetária e oportunidades de acesso a recursos distribuídos desigualmente na organização social do território metropolitano. Ao longo da história social e urbana da cidade do Rio de Janeiro, a dinâmica da infiltração expressou-se na forma favela como resultado de ações coletivas onde frações das classes populares conseguem acessar espaços intersticiais em meio a áreas que eles não teriam acesso se o puro preço da terra funcionasse como mecanismo de seleção. Mesmo em um espaço fortemente hierarquizado e pela especulação imobiliária, as relações e as práticas de apropriação e produção capitalista do espaço conviveram com as práticas da infiltração das camadas populares na forma de ocupações de terras públicas e privadas ou de mercados embebidos em instituições sociais compartilhadas pela população. Como exemplo disso temos as inúmeras favelas construídas na borda das sucessivas centralidades produzidas pela dinâmica de autosegregação das altas classes médias, como ocorrido em Copacabana-Ipanema-Leblon durante o período 1950/1970 ou mais recentemente na incorporação da Barra da Tijuca como frente de expansão do grande capital imobiliário.

O caráter desigual e combinado da ordem urbana da metrópole do Rio de Janeiro resulta da coexistência de diferentes dinâmicas de uso e produção do espaço residencial. Uma primeira dinâmica decorre da lógica do mercado capitalista comandada pela incorporação imobiliária sempre associada (direta ou indiretamente) a outros circuitos da acumulação urbana; uma segunda dinâmica resulta da articulação de um mix 
que pode envolver a produção por encomenda, a autoprodução, além do próprio mercado formal; e uma terceira resulta do uso de partes da cidade dentro da lógica fronteira (como mecanismo de gestão do exército industrial de reserva) mencionada anteriormente, cuja característica central é a presença de práticas de acesso ao solo urbano de invasão ou de mercado embebidas em relações de solidariedade e reciprocidade. Do ponto de vista morfológico, essa maneira de interpretar a dinâmica socioterritorial da metrópole do Rio de Janeiro nos levou a identificar um padrão de segregação residencial mais complexo do que o esperado pela hipótese da causação circular cumulativa, pois alicerçado em dupla gramática escalar: na microescala, com a proximidade territorial e a distância social entre as classes sociais, evidenciadas pela presença das favelas nas áreas de concentração do poder econômico e político e, na macroescala, com a concentração das camadas populares nas sucessivas periferias formadas a partir do núcleo da cidade do Rio de Janeiro.

\section{Metamorfoses da ordem urbana da metrópole do Rio de Janeiro}

O que ocorreu no período pós 1980? Examinamos várias dimensões das transformações da ordem urbana neste período. Os resultados empíricos apresentados em Ribeiro et alli (2015) nos levaram a concluir que apesar das macrotendências de transformação econômica, social e política mencionadas, o período 1980-2010 apresentou poucas mudanças na morfologia e na dinâmica de organização social do território metropolitano. Ao longo desses 30 anos, com efeito, constatamos sinais evidentes da continuidade da vigência do mecanismo de causação circular cumulativa cujo resultado é a manutenção do processo de segregação residencial baseado na dupla gramática escalar: a da distância social e proximidade 
territorial expressa na dicotomia favela-bairro e a da distância territorial e distância social materializada, por sua vez, no par núcleo-periferia. Examinaremos algumas evidências que justificam esta afirmação, apresentando em primeiro lugar o que ocorreu nas dinâmicas sócio-territoriais e posteriormente nas conexões entre os processos de segregação com os mecanismos de reprodução das desigualdades.

A Figura 1 abaixo expressa a permanência do padrão de segregação na metrópole ao longo do período 1980/2010.
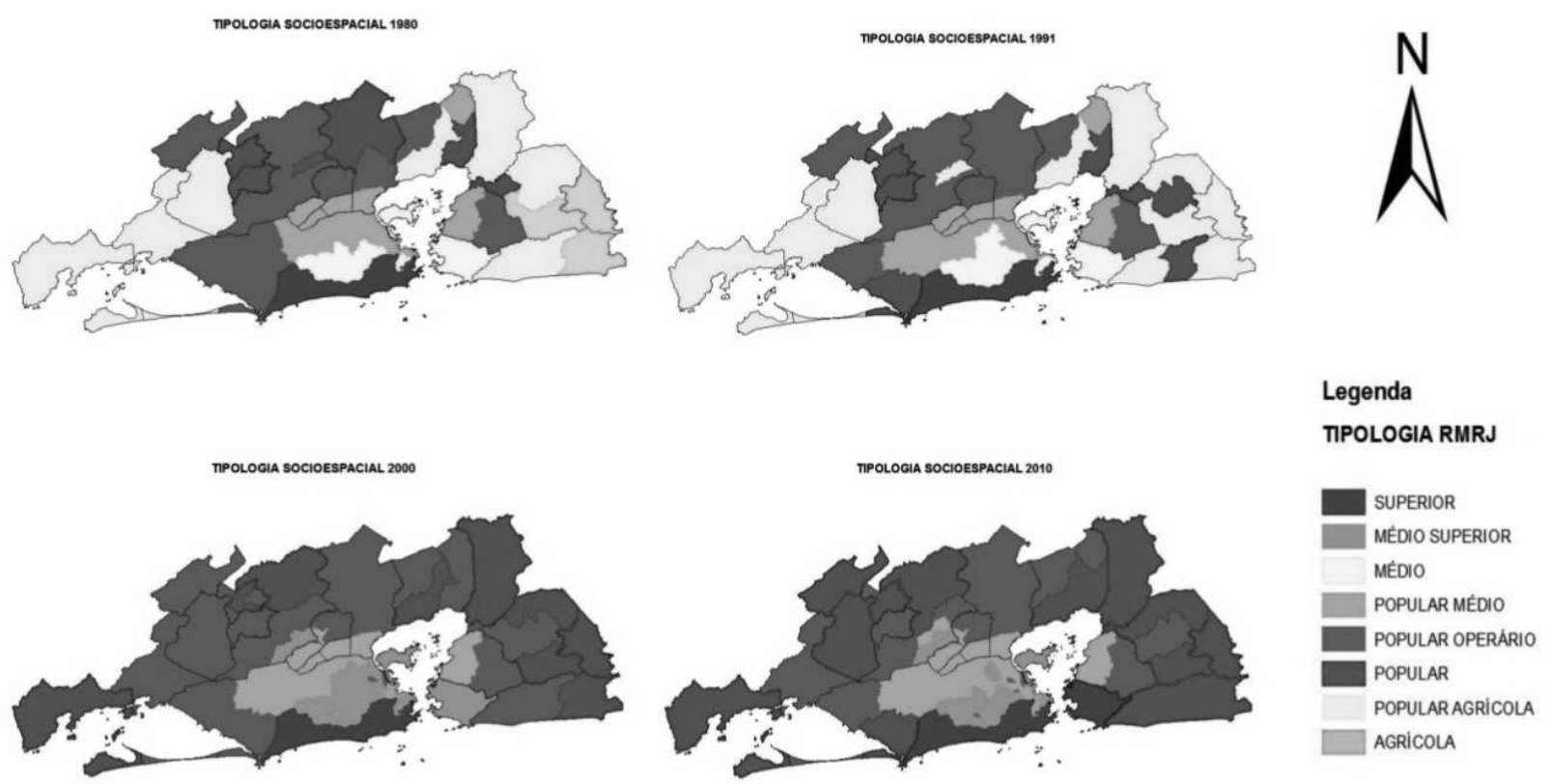

Figura 1. Tipologia socioespacial da Região Metropolitana do Rio de Janeiro Fonte: Ribeiro e Ribeiro (2015, p. 185). 
Os mapas resultam na análise da evolução da organização social do território metropolitano apresentada por Ribeiro e Ribeiro (2015) com base na tipologia socioespacial elaborada pelo Observatório das Metrópoles $^{15}$. O seu exame indica que observamos sinais de reprodução da dinâmica de concentração residencial das classes detentoras do poder econômico e social nas áreas superiores da metrópole. Isso tornou o espaço metropolitano mais polarizado na grande escala da organização social do território, em razão do movimento de mobilidade residencial da população, com a saída de camadas populares das áreas superiores localizadas na cidade do Rio de Janeiro - especialmente a Zona Sul e a Barra da Tijuca - para se instalarem na periferia metropolitana mais distante. Apesar das limitações dos dados censitários, Oliveira e Tavares (2015) demonstraram, com efeito, que entre 2000 e 2010 cerca de 60\% das mudanças de residência ocorridas das áreas superiores para a periferia metropolitana foram realizadas por trabalhadores e pequenos empregadores, dirigindo-se para espaços cujos moradores ocupavam posições sociais semelhantes às suas. $\mathrm{O}$ inverso foi também constatado pelos autores, ou seja, as pessoas que entram nas áreas superiores eram majoritariamente aquelas que ocupam as posições de detentoras do poder econômico e social.

Esse movimento certamente está relacionado com a expansão da lógica de mercantilização do solo urbano e da moradia, impulsionada pelo mercado imobiliário cuja expressão mais evidente é a elevação dos preços e dos aluguéis ${ }^{16}$. Cardoso e Lago (2015) constataram, objetivamen-

\footnotetext{
${ }^{15}$ Ver a descrição desta metodologia em Ribeiro e Ribeiro (2013) disponível em <http://www. observatoriodasmetropoles.net $/$ index.php?option $=$ com_k2\&view $=$ item\&id $=604$ :e-book-an\%C3\%A1 lise-social-do-territ\%C3\%B3rio\&ltemid=167\&lang=en >.

${ }^{16}$ Não dispomos de estatísticas sistemáticas e confiáveis sobre a valorização imobiliária ocorrida. Tomando como referência o índice FIPE ZAP (Fundação Instituto de Pesquisas Econômicas/ ZAP imóveis) levantado por Cardoso e Lago (2015) entre 2008 e 2013, o preço médio de venda elevou-se em 164,7\%, contra uma elevação de 32,5\% do IGP-M no período considerado. Os valores de aluguéis para imóveis tipo sala dois quartos (tipo predominante) também
} 
te, que após a estagnação dos anos 1990 ocorreu uma vigorosa retomada dos lançamentos imobiliários por incorporação - como evidencia o Gráfico 1 abaixo - impulsionados pelo aumento da renda e pelas reformas institucionais do sistema financeiro da habitação ${ }^{17}$. Passamos de um patamar médio de 4.000 unidades habitacionais lançadas até 2003 para 9.000 entre os anos de 2005 e 2006, 11.000 em 2008 e 2009 (anos em que ocorreu um impacto negativo da crise), chegando a quase 18.000 unidades em 2010. Um pouco mais de 60\% do total de unidades lançadas concentram-se no eixo Barra da Tijuca/Jacarepaguá (principal frente de expansão urbana aberta no final da década de 1970 e durante os anos 1980) e apenas pouco mais de $10 \%$ na área superior consolidada conformada pelo eixo Zona Sul/Tijuca.

apresentaram alta significativa ao longo, principalmente, da segunda metade da década, acelerando a partir de 2007/2008. A elevação dos preços no Rio de Janeiro, acumulada até 2014, foi de $137 \%$, contra um crescimento do IGP-M de $42,8 \%$.

${ }^{17}$ Expansão significativa da disponibilização pelos bancos dos recursos do SBPE e do Sistema Financeiro da Habitação em razão do crescimento da emissão de Certificado de Recebíveis Imobiliário e criação dos Fundos Imobiliários. 
Gráfico 1. Unidades lançadas na Cidade do Rio de Janeiro (2001-2010)

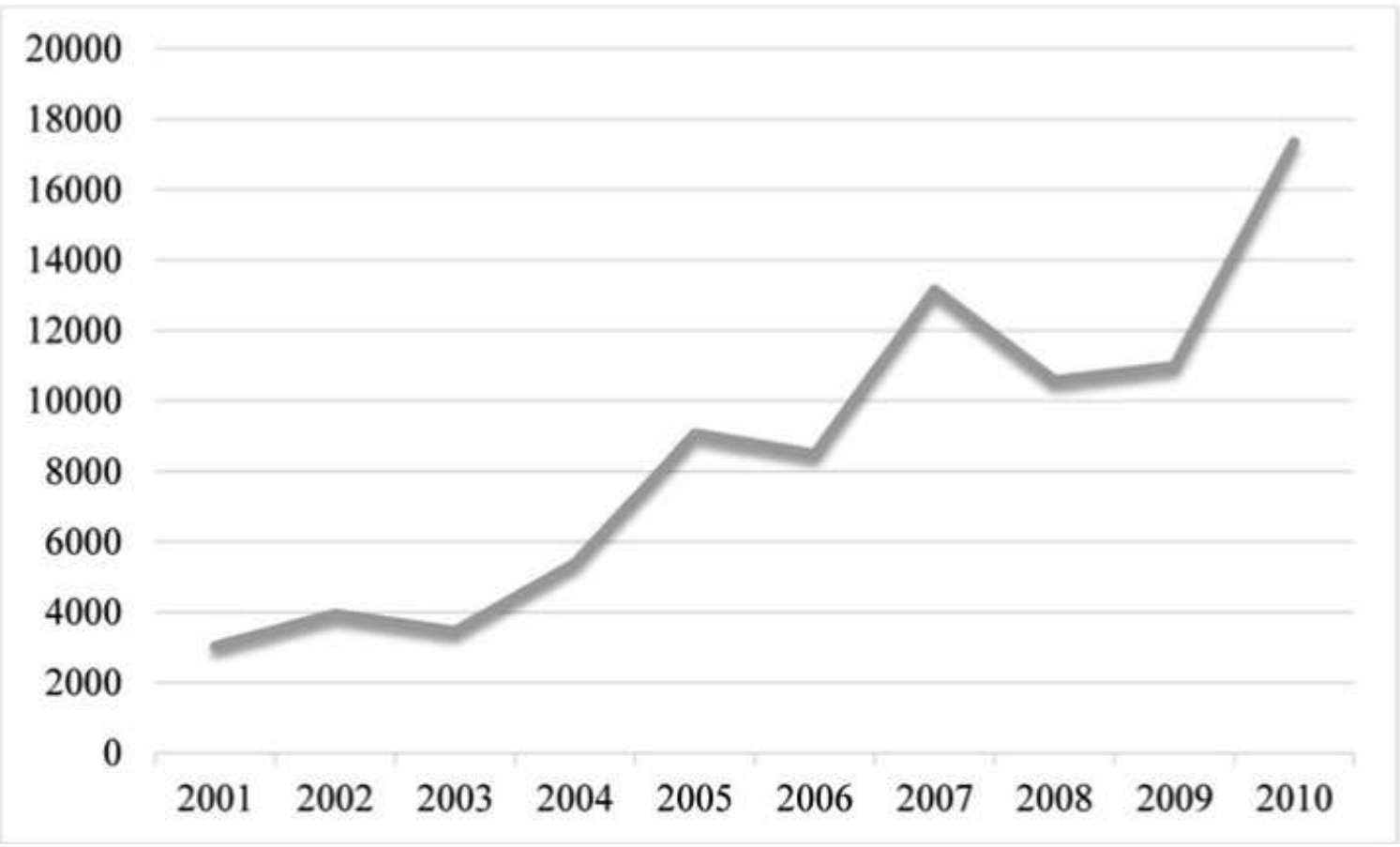

Fonte: Associação dos Dirigentes do Mercado Imobiliário (ADEMI).Extraído de Cardoso e Lago (2015, p. 346).

Simultaneamente, ao longo desse período também observamos a reprodução da dinâmica de periferização do espaço metropolitano, embora tenham emergido tendências à diversificação social com a constituição de enclaves de espaços da alta classe média na periferia metropolitana consolidada, especificamente a região da Baixada Fluminense. Porém, esses enclaves não alteram expressivamente a distância social em relação aos espaços mais centrais, fato que se evidencia pela manutenção do perfil geral da composição social do conjunto da periferia se observado o que está colocado na Figura 1. O surgimento dos mencionados enclaves na periferia metropolitana corresponde ao processo de estratificação do mundo urbano das classes médias, que vem ocorrendo como resultado do fenômeno da enorme expansão do ensino de nível superior e criando o fenômeno 
conhecido como over education ${ }^{18}$, pelo qual já não há mais relação assegurada e direta entre posição social e poder econômico e político.

Apesar da forte valorização imobiliária nas áreas centrais da metrópole, observamos a continuidade do processo conflituoso de infiltração pelas camadas populares nos espaços superiores por meio do crescimento das favelas na cidade do Rio de Janeiro. Vejamos alguns dados: em trabalho anterior (Ribeiro; Lago, 2001), tínhamos constatado a expansão das favelas no período 1980 e 2000, expresso no fato de que o crescimento da população morando nesses espaços tinha sido superior ao verificado no conjunto da cidade, invertendo a tendência em curso nos anos 1970. Entre 2000 e 2010 verifica-se a continuidade desse movimento, pois se a população da cidade cresceu apenas 5\%, aquela morando em favelas se expandiu 19\%, representando hoje cerca de $23 \%$ dos residentes do Rio de Janeiro. Ou seja, não obstante a melhoria da renda e do emprego ocorrida nos anos recentes, continuou a crescer este tipo de moradia, fato concentrado essencialmente em dois eixos: a Zona Sul da cidade, que se constituiu na área de expansão da auto segregação no período anterior e na qual as favelas cresceram 28\% enquanto a população diminuiu de 1\%; e o eixo Barra da Tijuca/Jacarepaguá, nova fronteira de expansão do capital imobiliário, e portanto da auto-segregação, onde a população moradora em favela cresceu 53\% em 10 anos, acompanhando a explosão demográfica de $28 \%{ }^{19}$.

\footnotetext{
${ }^{18}$ Uma ilustração do nosso argumento: a renda per capta domiciliar entre um profissional de nível superior morador do bairro da Lagoa Rodrigo de Freitas, na Zona Sul é 6 vezes maior que a renda de um morador equivalente do município de Duque de Caxias, típico espaço da periferia consolidada. A dissociação entre educação, posição social e condição social no Brasil metropolitano contemporâneo foi competentemente demonstrada na tese de doutoramento de Marcelo Gomes Ribeiro intitulada "Educação, Posição de Classe e Território: Uma análise das desigualdades de renda em regiões metropolitanas do Brasil". Ver: Ribeiro (2012).

${ }^{19}$ Os dados mencionados são oriundos dos censos demográficos e tabulados por Cavalieri e Vial (2012).
} 
É importante ressaltar, contudo, que o processo de infiltração vem ganhando novos contornos nos últimos 10 anos, cujo resultado é a tendência à transformação das condições sociais com o aumento de nível de renda domiciliar, sem alterar, porém, a essência da composição social das áreas das favelas. Com efeito, Lago e Cardoso (2015) demonstraram que a continuidade de barreiras institucionais (violência, estigma socioterritorial, entre outras) continuou operando como mecanismo seletivo à plena integração das favelas à cidade, não obstante as tendências de expansão de práticas de mercantilização na produção da moradia nesses espaços. Objetivamente, os autores, comparando as mudanças da composição social, constataram que a diversificação social dos espaços populares da periferia não se observa nos espaços das favelas. Apesar das melhorias da renda do conjunto da cidade e em especial do mundo popular, as favelas continuam resultando da dinâmica de infiltração social das camadas populares mais precarizadas no mercado de trabalho aos espaços superiores que concentram recursos na forma de renda, emprego e oportunidade. $\mathrm{O}$ resultado é manutenção da gramática de segregação residencial fundada na distância social e proximidade territorial com os espaços superiores da metrópole. O gráfico abaixo expressa este fato. 
Gráfico 2. Rendimento médio total por favela e não favela segundo a organização social do território da Região Metropolitana do Rio de Janeiro - 2000 e 2010

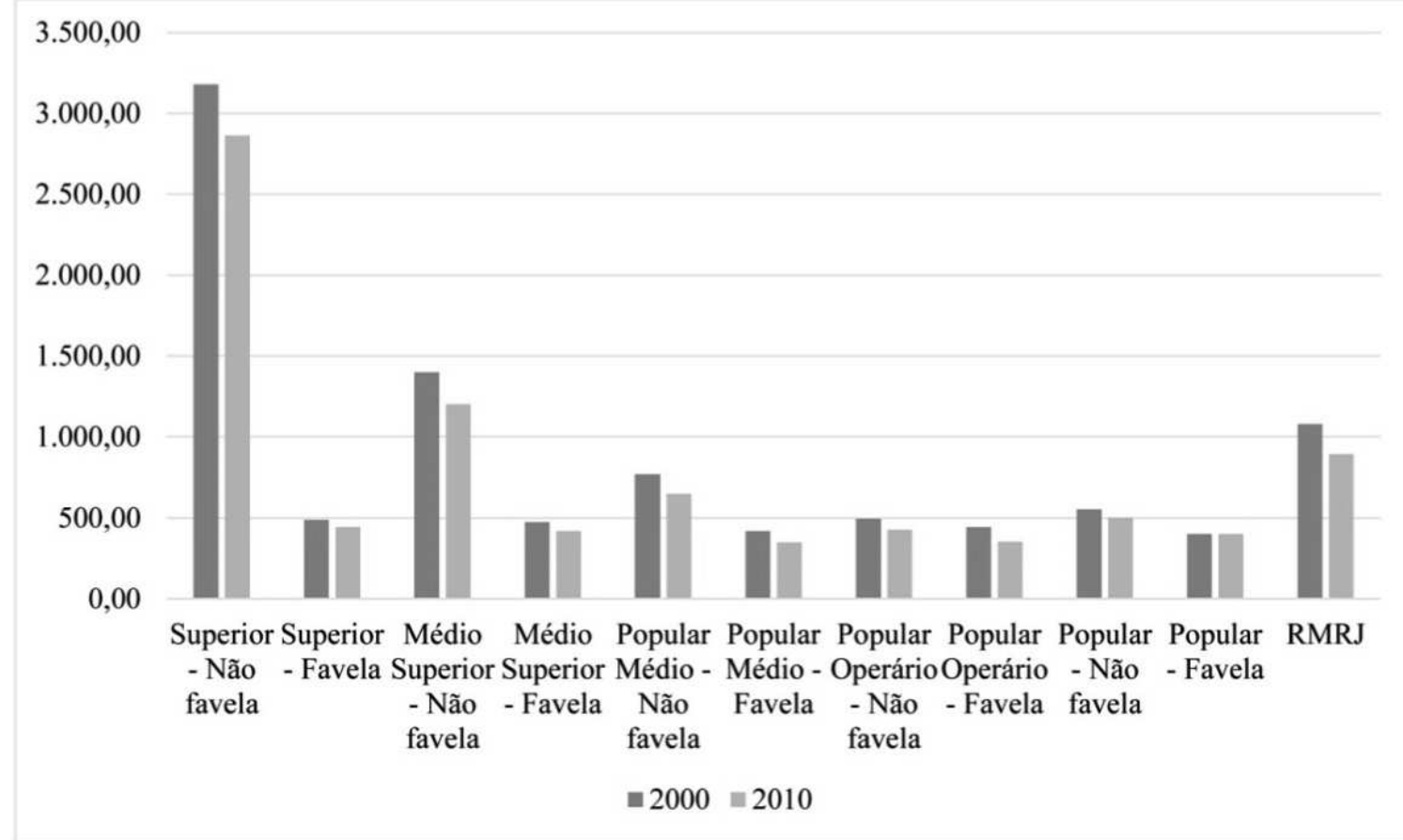

Fonte: Ribeiro e Ribeiro (2015, p. 192).

Os moradores de não-favela do tipo socioespacial "superior" ganhavam em média, (tanto em 2000 quanto em 2010,) 6,4 vezes mais que os moradores de favela. Em relação ao tipo "médio superior" essa relação era de 2,9 vezes. Os moradores de não-favela do tipo "popular médio" ganhavam em média o dobro dos moradores de favela. Já no tipo "popular operário" e "popular" a diferença é de apenas de 20\% em favor dos moradores de não-favela. Essa constatação nos possibilita compreender que as diferenças entre favela e não-favela obedece à hierarquia socioespacial da metrópole do Rio de Janeiro, de acordo com o seu padrão de organização social do território segundo o modelo núcleo-periferia. Quanto mais longe do núcleo metropolitano, mais proximidade há entre as condições sociais dos moradores de favela e dos moradores de não- 
-favela. Porém, no núcleo metropolitano e nos tipos socioespaciais próximos ao núcleo, a diferença entre moradores de favela e de não-favela é muito expressiva.

Quando examinamos as desigualdades de condições urbanas de vida tendo como base o Índice de Bem-Estar Urbano (IBEU) produzido pelo Observatório das Metrópoles a partir de dados do Censo Demográfico de 2010 do $\mathrm{IBGE}^{20}$, constatamos a manutenção do quadro de fortes desigualdades entre as áreas centrais e a periferia, não obstante a relativa desconcentração espacial dos investimentos urbanos - como por exemplo em saneamento ambiental - que ocorreram após 1980. Algo que está evidenciado no mapa que consta na Figura 2. Assim, conforme as observações de vários analistas, na metrópole fluminense mantêm-se fortes relações entre a segregação residencial e as desigualdades das condições urbanas de vida, tal qual foi descrito nos estudos seminais relativos aos anos 1970 mencionados anteriormente.

\footnotetext{
$\overline{{ }^{20} \text { As desigualdades }}$ de condições urbanas de vida expressas neste mapa foram estimadas através do índice de Bem-Estar Urbano - IBEU produzido pelo Observatório das Metrópoles. Consultar a este respeito: $<$ http://www.observatoriodasmetropoles.net/index.php?option $=$ com_k2\& view $=$ item\&id $=642 \% 3 \mathrm{Alan} \% \mathrm{C} 3 \% \mathrm{~A} 7 \mathrm{amento}$-do-livro-\%E2\%80\%9C\%C3\%ADndice-de-bem-estar-urbano-\%E2\%80\%93-ibeu\%E2\%80\%9D\&Itemid=167\&lang=pt>
} 


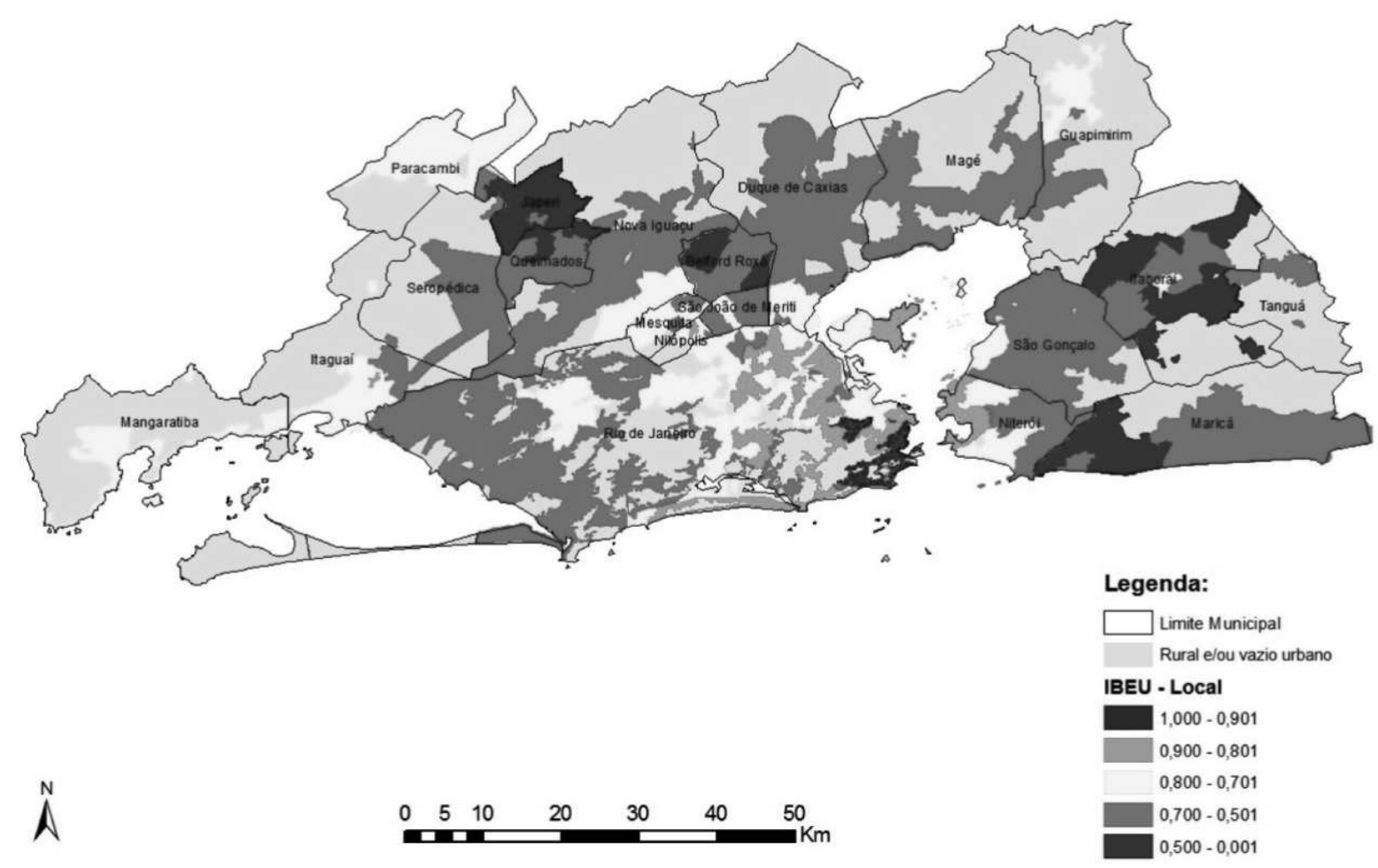

Figura 2. Índice de Bem-Estar Urbano na Região Metropolitana do Rio de Janeiro - 2010 Fonte: Nery Jr. e Costa (2015, p. 416)

Analisando de forma mais detalhada os índices que compõem o IBEU da Região Metropolitana do Rio de Janeiro ${ }^{21}$, verificamos que somente 93 áreas de ponderação ( $27 \%$ do total) apresentam índices de bem-estar urbano mais elevados, classificados como bom e muito bom, que significam respectivamente níveis entre 0,801-0,900 e 0,901 - 1. Nas áreas de ponderação pertencentes a esses níveis, residem 2.751 .537 pessoas, ou seja apenas 23,18\% da população da RMRJ em 1.026.866 domicílios.

\footnotetext{
${ }^{21}$ A Região Metropolitana do Rio de Janeiro (RMRJ) é composta atualmente por 20 municípios contendo um total de 338 áreas de ponderação e uma população de 11.872 .164 habitantes, porém com características de bem-estar urbano bastante heterogêneas.
} 
Já as faixas inferiores, com níveis classificados como ruim e muito ruim, representadas no mapa pelas cores laranja e vermelha, respectivamente, são compostas por 135 áreas de ponderação (cerca de 39,94\% do total). E possui uma população de 5.571 .678 pessoas, que correspondem a 46,93\% da população da região metropolitana, residindo em 1.768 .066 domicílios contidos em áreas de ponderação detentoras de níveis de bem-estar urbano entre 0,001 - 0,500 e 0,501 - 0,700. O nível classificado como médio no IBEU está representado no mapa pela cor amarela e apresenta índices de bem-estar urbano entre 0,701 - 0,8. Está presente em 110 áreas de ponderação correspondendo a 32,54\% do total da região metropolitana. Essas áreas possuem juntas uma população de 3.099.769 pessoas, cerca de $26,11 \%$ da RMRJ residindo em 1.167.042 domicílios.

Outro elemento que indica a manutenção do mecanismo de causação circular cumulativa decorre dos resultados da análise sobre a relação entre organização social do território e a reprodução das desigualdades de oportunidades escolares (Ribeiro e Kaztman, 2008; Ribeiro et alli., 2010) e ocupacionais (Ribeiro, Rodrigues e Correa, 2008). Constatamos, por exemplo, que crianças de origem social semelhantes (em termos de escolaridade da mãe, renda per capita familiar, gênero e cor) cursando a oitava série do ensino fundamental em escolas públicas têm risco 30\% maior de insucesso escolar quando moram em favelas na cidade do Rio de Janeiro (Alves, Franco Junior e Ribeiro, 2008). Ao mesmo tempo, nesta mesma pesquisa detectamos o fato até certo ponto surpreendente de que as crianças moradoras em favelas localizadas nos bairros mais auto-segregados não se beneficiavam desta localização em termos de maiores chances de aquisição do capital escolar se comparadas com as moradoras em favelas dos bairros médios e mesmo populares, deixando claro os efeitos dos meios sociais constituídos pelos processos de segregação residencial na diferenciação das chances de aquisição do capital escolar, fato que 
aponta para tendência à reprodução inter-geracional das desigualdades sociais. O trabalho realizado por Koslinski, Alves, Heredia e Regis (2015) - com a utilização de indicadores e procedimentos similares - confirmou empiricamente para a escala metropolitana os efeitos negativos no conjunto da segregação residencial e das precárias condições urbanas e habitacionais no desempenho escolar de crianças e jovens do ensino. No que concerne às desigualdades de oportunidades ocupacionais, a pesquisa indica que os adultos de 25 a 59 moradores em bairros populares onde predomina baixo grau de concentração de capital educativo apresentam um risco 18,2 \% maior de estar em ocupação precária no mercado de trabalho, quando comparado com aqueles que possuem características individuais semelhantes, mas que moram em espaços que, ao contrário, concentram mais capital educativo. Esta pesquisa mostrou também que existe uma tendência que faz com que o rendimento da ocupação seja 37,92\% menor nestes espaços, obedecendo a mesma comparação.

Há, portanto, fortes e relevantes evidências empíricas dos efeitos dos diferentes contextos sociais gerados pela segregação residencial nas escalas núcleo-periferia e favela-bairro na reprodução da estrutura de desigualdades em termos de acesso ao bem-estar urbano e às oportunidades, fato que nos permite considerar a permanência da ação da causação circular cumulativa como fundamento mesmo da ordem urbana imperante na metrópole do Rio de Janeiro.

\section{Conclusão: as forças da ordem urbana}

Como vimos, apesar dos três distintos ciclos macroeconômicos compreendidos no longo período entre 1980-2010, não se observam mudanças substanciais na organização social do território da metrópole do Rio de Janeiro em relação ao padrão segregado e desigual constituído 
na fase da industrialização por substituição de importação. Poder-se-ia argumentar que tal fato decorreria dos efeitos esperados da inércia da forma espacial em relação às mudanças sociais. Nossa proposição explicativa, porém, incita uma busca de outra natureza. Ela procura identificar as conexões entre o padrão de organização social do território com a dinâmica de reprodução das relações sociais de dominação e desigualdades sociais, como enunciado no conceito de ordem urbana apresentado anteriormente. Nesse sentido, sem pretender realizar uma análise exaustiva, buscamos evidenciar a economia política da dinâmica de organização do território, que, baseada em um conjunto de forças econômicas, sociais e políticas, configura a ordem urbana na metrópole do Rio de Janeiro.

Em primeiro lugar, temos o quadro de fragmentação da governança urbana da metrópole. Enquanto se mantém o padrão tradicional da política urbana na metrópole fundada no binômio clientelismo-patrimonialismo - como mostraram Britto (2015) e Rojas (2015) - o núcleo metropolitano conformado pela cidade do Rio de Janeiro vem sendo objeto, desde o início dos anos 1990, de um processo de modernização liberal (Santos, 2015) da forma de governo e de intervenção pública que recicla as condições políticas da acumulação urbana, além de manter o quadro de fragmentação institucional na governança metropolitana. A intervenção pública na preparação da cidade do Rio de Janeiro para sediar os megaeventos Copa do Mundo de Futebol 2014 e Jogos Olímpicos de Verão 2016 como novos ciclos de mercantilização da cidade, que atualizam e recompõem as forças da acumulação urbana, no nosso argumento, estão na base da reprodução do mecanismo de causação circular cumulativa. Foram abandonados os compromissos universalistas e redistributivos expressos no plano diretor aprovado em 1991, passando o governo da cidade a se orientar por ações consideradas estratégicas para torná-la competitiva no mercado global de consumo de serviços, particularmen- 
te aqueles relacionados com o turismo de divertimento. A política urbana passou a concentrar suas ações habilitadoras do mercado - em termos de investimento e de regulação urbana - na Barra da Tijuca, na Área Portuária e na Zona Sul, alimentando, assim, o mecanismo da causação circular e cumulativa das desigualdades urbanas. Paralelamente, as mudanças institucionais ocorridas em 2010 nas relações entre o poder público municipal e as empresas de ônibus na cidade do Rio de Janeiro - analisadas por Matela (2015) - transformam o precário regime de permissão patrimonialista até então em vigor em um moderno sistema de contratualização. Formalmente, os marcos institucionais do laissez-faire urbano que imperou na cidade desde os anos 1950 são abandonados, mas o sentido político da mudança é, de fato, a renovação sob novas bases - racionalizadas e empresariais - do poder do capital concessionário nos serviços de transportes coletivos da cidade. Nesse sentido, podemos também falar de uma ação de modernização neoliberal atendendo às necessidades do novo ciclo da acumulação urbana.

Como contrapartida, no plano da sociedade, a reprodução do mecanismo de causação circular cumulativa encontra sustentação na partição da cultura cívico-política e das modalidades de exercício da cidadania política entre as áreas mais centrais da metrópole e a periferia. Com efeito, como evidenciado em Ribeiro e Correa (2015) e em Ribeiro e Santos Junior (1996), há uma nítida partição do tecido associativo e do sistema de participação sociopolítico da metrópole fluminense entre as áreas mais centrais da metrópole - Zona Sul e Norte (Tijuca e Vila Isabel) da cidade do Rio de Janeiro e a cidade de Niterói - nas quais predominam elevados índices de adesão dos moradores ao padrão corporativo (sindicato, associação profissional e partido) -, enquanto na periferia metropolitana prevalece o padrão comunitário-popular (entidades filantrópicas e religiosas e associação de moradores). Tal fato se expressa no maior poder de mobilização e de reivindicação dos moradores das áreas conformadas pela auto-segregação, 
já beneficiadas pela intervenção seletiva do poder público em termos de investimento e de regulação. Tal participação tem como contrapartida forte diferenciação nas modalidades do exercício da cidadania política traduzida em modalidades distintas de conexões e de representações políticas entre as áreas da metrópole. Enquanto na periferia tende a prevalecer o clientelismo político através do qual a conexão se realiza pela dinâmica favor-voto e o padrão localista de representação política, nas áreas centrais predominam a competição eleitoral e o padrão mais universalista de representação. $\mathrm{O}$ resultado da partição territorial cívico-política é a forte conexão entre o padrão de segregação residencial e a reprodução das desigualdades sociais e urbanas entre as áreas centrais e periféricas da metrópole fluminense, como empiricamente demonstrado por Correa (2011).

Fecha-se, então, o círculo da causação circular e cumulativa da desigualdade: a segregação do poder econômico, social e político se transformando em poder de segregação expresso na capacidade das classes proprietárias em ordenar a seu favor a ocupação e o uso do solo urbano, isto é, tornar seletiva a apropriação do território e dos recursos nele inscritos - bem-estar, renda, riqueza, oportunidade e poder. Isto significa dizer que o mecanismo da causação circular e cumulativa das desigualdades como base da dinâmica de organização social do território metropolitano não decorre de um fato contingencial como, por exemplo, o regime ditatorial das décadas de 1960, 1970 e parte dos 1980. Categoricamente, se a redemocratização do país, iniciada na segunda metade dos anos 1980, alterou o padrão concentrado de alocação territorial dos investimentos urbanos em favor da periferia, como mostraram alguns trabalhos ${ }^{22}$, as desigualdades intrametropolitanas de bem-estar, riqueza, renda, oportunidades e poder não se alteraram, como evidenciado anteriormente. Um conjunto

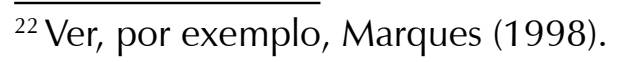


de forças de natureza sociopolítica mantém a lógica da causação circular e cumulativa das desigualdades núcleo-periferia que se deslocam da dimensão quantitativa para a qualitativa. Como mostraram Porto (2003) e Britto e Porto (2000), o padrão fragmentado, focalizado e descontínuo das intervenções públicas que ocorreram na periferia metropolitana a partir de 1984 em matéria de saneamento ambiental, impulsionadas pelas reivindicações populares, promoveu investimentos incapazes de mudarem de fato a precariedade das condições sanitárias e de drenagem da periferia. Esse padrão decorre da submissão da intervenção pública nos espaços populares - periferia metropolitana e favela - à lógica do governo da exceção que transforma permanentemente a reivindicação social em política assistencialista, cujo substrato é a fragmentação cívico-política do mundo popular. Em contrapartida, nas áreas centrais da metrópole o padrão de provisão de serviços e de infraestrutura se aproxima da política universalista fundada, ao contrário, no corporativismo territorial das altas classes médias como mostram Ribeiro (2002) e Malerba (2005).

Há, portanto, uma conexão intrínseca entre o mecanismo de causação circular e cumulativa e o poder de segregação, na medida em que o seu exercício se concretiza pelo domínio social e político da centralidade urbana da metrópole como riqueza oligárquica ${ }^{23}$ (Hirsch, 1976), isto é, em um conjunto de recursos materiais e imateriais de natureza posicional coagulados nas áreas centrais que, por esse motivo, não são generalizáveis para a periferia, não obstante a melhoria das condições sociais e urbanas de vida da população. Em consequência, os padrões de organização do

\footnotetext{
${ }^{23} \mathrm{O}$ conceito de riqueza oligárquica foi elaborado por Roy Harrod e utilizado por Hirsch (1976) para formular uma teoria sobre os limites sociais do crescimento. Haveria, de acordo com o autor, duas diferentes riquezas, denominadas "democrática" e "oligárquica". A primeira o tipo de domínio sobre recursos que, em princípio, está disponível para todos em relação direta com a intensidade e eficiência de seus esforços. Já a riqueza oligárquica, em contrapartida, não tem qualquer relação com os esforços e nunca está disponível para todos.
} 
território expressos nas duas gramáticas de segregação - distância social/ proximidade territorial, distância social/distância territorial - mencionadas anteriormente, resultam não da ausência de desenvolvimento, mas da reprodução das relações de poder social, econômico e político que sustentam a ordem urbana, alicerçada na manutenção da escassez urbana absoluta e relativa,e fundamentam a captura de várias modalidades de class-monopoly rent.

Luiz Cesar de Queiroz Ribeiro é Doutor em Arquitetura e Urbanismo pela Universidade de São Paulo, Professor titular do Instituto de Pesquisa e Planejamento Urbano e Regional da Universidade Federal do Rio de Janeiro - IPPUR/UFRJ, e Coordenador do INCT Observatório das Metrópoles. \lcqr@terra.com.br

\section{Referências}

1. ABREU, M. de A. Evolução Urbana do Rio de Janeiro. Rio de Janeiro: IPLANRIO/Jorge Zahar, 1987.

2. AREND, M. O Brasil e o longo século XX: condicionantes sistêmicos para estratégias nacionais de desenvolvimento. Disponível em: <http://www.gpepsm. ufsc.br/html/arquivos/Texto_para_Discussao_2012-n1_Arend.pdf 2012 2 . Acesso em: 18 fev. 2014

3. ALVES, F.; FRANCO JUNIOR, F. C.; RIBEIRO, L. C. Segregação residencial e desigualdade escolar no Rio de Janeiro. In: RIBEIRO, L. C.; KAZTMAN, R. (Org.). A Cidade contra a Escola. Segregação Urbana e desigualdades educacionais em grandes cidades da América Latina. Rio de Janeiro: Letra Capital/Observatório das Metrópoles, 2008. p. 91-118. Disponível em: <http://web.observatoriodasmetropoles.net $/$ index.php?option $=$ com_abook \&view $=$ book \& catid $=1 \% 3$ Alivros\&id $=87$ \%3Aa-cidade-contra-a-escola\&ltemid=123\&lang=pt>. Acesso em: 14 jan. 2016.

4. BOURDIEU, P. La Distinction. Critique social du jugement. Paris: Editions Minuit. 1979.

5. BRITTO, A. L. A gestão do saneamento ambiental: entre o mercado e o direito. In: RIBEIRO, L. C. (Org.). Rio de Janeiro: Transformações na Ordem Urbana. Rio de Janeiro: Letra Capital, 2015. p. 484-514. Disponível em: < http://transformacoes.observatoriodasmetropoles.net/livro/rio-de-janeiro/>. Acesso em: 14 jan. 2016. 
6. BRITTO, A. L.; PORTO, H. R. Universalização e privatização: os dilemas da Política de Saneamento na Metrópole do Rio de Janeiro. In: RIBEIRO, L. C. (Org.) O Futuro das Metrópoles: Desigualdades e Governabilidade. Rio de Janeiro: Editora REVAN/Observatório das Metrópoles, 2000. p. 457-478. Disponível em: <http://web.observatoriodasmetropoles.net/index. php?option $=$ com_abook \&view $=$ book \&catid $=1 \% 3$ Alivros $\& i d=62 \% 3$ Ao-futuro-das-metropoles\&Itemid=123\&lang=pt $>$. Acesso em: 14 jan. 2016.

7. CARDOSO, A. L.; LAGO, L. C. Dinâmica imobiliária: Estado e o capital imobiliário. In: RIBEIRO, L. C. (org.). Rio de Janeiro: Transformações na Ordem Urbana. Rio de Janeiro: Letra Capital, 2015. p. 320-353.Disponível em: < http:// transformacoes.observatoriodasmetropoles.net/livro/rio-de-janeiro/> . Acesso em: 14 jan. 2016.

8. CASTEL, R. Les Métamorphoses de la Question Sociale. Une chronique du salariat. Paris: Fayard, 1995.

9. CASTELLS, M. La Question Urbaine. Paris: François Maspero. 1975.

10. CAVALIERI, F.; VIAL, A. Favelas na cidade do Rio de Janeiro: o quadro populacional com base no Censo 2010.Coleção Estudos Cariocas, Rio de Janeiro, n. 20120501, mai. 2012.

11. CORRÊAA, F. S. Conexões eleitorais, Conexões territoriais: as bases socioterritoriais da representação política na metrópole fluminense. 2011. Dissertação (Mestrado em Planejamento Urbano e Regional) - Instituto de Pesquisa e Planejamento Urbano e Regional, Universidade Federal do Rio de Janeiro, Rio de Janeiro.

12. DAIN, S. O Rio de todas as crises - crise econômica. Série Estudos, Rio de Janeiro, n. 80, dez. 1990.

13. GOLDTHORPE, J. H. Social mobility and class structure in modern Britain. , Oxford: Clarendon Press (Oxford University Press), 1980

14. FERNANDES, F. A revolução burguesa no Brasil. Rio de Janeiro: Zahar, 1976.

15. FIORI, J. L. O Voo da Coruja: Uma leitura não liberal da crise do estado desenvolvimentista. Rio de Janeiro: EDUERJ, 1995.

16. HARVEY, D. Social Justice and the City. Baltimore: John Hopkins, 1973.

17. HARVEY, D. Class-monopoly rent, finance capital and the urban revolution. Regional Studies, v.8, n. 3-4, p. 239-255, 1974.

18. HIRSCH, F. Limites sociais do crescimento. Rio de Janeiro: Zahar, 1976.

19. KATZMAN, R. "La calidad de las relaciones sociales en las grandes ciudades de América Latina: viejos y nuevos determinantes" Revista Pensamiento Latinoamericano, Numero 1, 2o Epoca, del 15/10/2007. 
20. KOSLINSKI, M. C.; ALVES, F.; HEREDIA, P. H; REGIS, A. Segregação residencial, moradia e desigualdade escolar. In: RIBEIRO, Luiz Cesar de Queiroz (Org.). Rio de Janeiro: Transformações na Ordem Urbana. Rio de Janeiro: Letra Capital, 2015.p. 389-415. Disponível em: < http://transformacoes.observatoriodasmetropoles.net/livro/rio-de-janeiro/>. Acesso em 14 jan. 2016.

21. LAGO, L. C.; CARDOSO, A. L. Dinâmica imobiliária: as classes sociais e a habitação. In: RIBEIRO, Luiz Cesar de Queiroz (Org.). Rio de Janeiro: Transformações na Ordem Urbana. Rio de Janeiro: Letra Capital, 2015. p. 354-388. Disponível em: <http://transformacoes.observatoriodasmetropoles.net/livro/rio-dejaneiro/>. Acesso em 14 jan. 2016.

22. LESSA, C.; DAIN, S. Capitalismo associado: algumas referências para o tema Estado e Desenvolvimento. In: BELUZZO, L. G.; COUTINHO, R. (Orgs.). Desenvolvimento capitalista no Brasil: Ensaios sobre a crise. Volume 1. Campinas: Unicamp-IE, 1984. p. 214-228.

23. LESSA, C. O Rio de Todos os Brasis. Uma reflexão em busca da auto-estima. Rio de Janeiro: Record, 2000.

24. MALERBA, J. Segregação do Poder, Poder de Segregação. Democracia, desigualdade e participação na dinâmica de acumulação urbana na metrópole do Rio de Janeiro. 2005. Dissertação (Mestrado em Planejamento Urbano e Regional) - Instituto de Pesquisa e Planejamento Urbano e Regional, Universidade Federal do Rio de Janeiro, Rio de Janeiro.

25. MARQUES, E. C. Redes Sociais e Permeabilidade do Estado: instituições e atores políticos. 1998. Tese (Doutorado em Ciências Sociais) - Instituto de Filosofia e Ciências Humanas, Universidade Estadual de Campinas. São Paulo,

26. MATELA, I. P. A gestão dos transportes: a renovação do pacto rodoviarista. In: RIBEIRO, L. C. (Org.). Rio de Janeiro: Transformações na Ordem Urbana. Rio de Janeiro: Letra Capital, 2015. p. 515-543.Disponível em: < http://transformacoes. observatoriodasmetropoles.net/livro/rio-de-janeiro/>. Acesso em: 14 jan. 2016.

27. MCKENZIE, R. D. A comunidade humana abordada ecologicamente. In: DONALD, P. (Org.). Estudos de Ecologia Humana. Tomo I. São Paulo: Livraria Martins Fontes, 1970. p. 95-110.

28. MYRDAL, G. Teoria econômica e regiões subdesenvolvidas. Rio de Janeiro: Saga, 1968.

29. NUNES, E. A Gramática Política do Brasil. Clientelismo e Insulamento burocrático. Rio de Janeiro.: Jorge Zahar Editores. 1997.

30. OliVEIRA, F. de. O Estado e o Urbano no Brasil. Espaços e Debates, n. 6, 1982. 
31. OLIVEIRA, R. A.; TAVARES, É. Transformações demográficas: os movimentos da população no território. In: RIBEIRO, Luiz Cesar de Queiroz (Org.). Rio de Janeiro: Transformações na Ordem Urbana. Rio de Janeiro: Letra Capital, 2015. pp. 221-254. Disponível em: < http://transformacoes.observatoriodasmetropoles. net/livro/rio-de-janeiro/>. Acesso em: 14 jan. 2016.

32. PORTO, H. R. Saneamento e Cidadania. Trajetórias e efeitos das políticas de saneamento na Baixada Fluminense. Rio de Janeiro: FASE/Observatório das Metrópoles, 2003.

33. RIBEIRO, L. C. Acumulação urbana e a cidade. Impasses atuais da política urbana. In: ANPOCS (Org.). Ciências Sociais Hoje. São Paulo: ANPOCS/CORTEZ, 1986. p. $53-78$

34. RIBEIRO, L. C. Dos cortiços aos condomínios fechados. As formas de produção da moradia na cidade do Rio de Janeiro. Rio de Janeiro: Civilização Brasileira, 1997. Disponível em: <http://web.observatoriodasmetropoles.net/ index.php?option $=$ com abook \&view $=$ book \&catid $=1 \% 3 \mathrm{Alivros} \& \mathrm{id}=69 \% 3 \mathrm{Ad}$ os-corticos-aos-condominios-fechados\&ltemid=123\&lang=pt $>$. Acesso em: 14 jan. 2016.

35. RIBEIRO, L. C. Cidade desigual ou cidade partida? Tendências da metrópole do Rio de Janeiro. In: RIBEIRO, L. C. (Org.). O Futuro das Metrópoles: Desigualdades e Governabilidade. Rio de Janeiro: Revan/Observatório das Metrópoles, 2000. p. 63-98. Disponível em: < http://web.observatoriodasmetropoles.net/ index.php?option $=$ com_abook \&view $=$ book \&catid $=1 \% 3$ Alivros \&id $=62 \% 3 \mathrm{Ao}-$ futuro-das-metropoles\&ltemid=123\&lang=pt>. Acesso em: 14 jan. 2016.

36. RIBEIRO, L. C. Segregação, acumulação urbana e poder: classes sociais e desigualdades na metrópole do Rio de Janeiro. Cadernos IPPUR, ano XV, n. 2, ago./dez. 2001.

37. RIBEIRO, L. C. Transformações da Ordem Urbana na Metrópole LiberalPeriférica: 1980-2010. Hipótese e estratégia teórico-metodológica para estudo comparativo. Reprodução em fotocópia. Rio de Janeiro, 2013.

38. RIBEIRO, L. C.; CORRÊA, F. Cultura política, cidadania e representação na urbs sem civitas. In: RIBEIRO, L. C. (Org.). Rio de Janeiro: Transformações na Ordem Urbana. Rio de Janeiro: Letra Capital, 2015. p. 197-220. Disponível em: <http://transformacoes.observatoriodasmetropoles.net/livro/rio-de-janeiro/>. Acesso em: 14 jan. 2016.

39. RIBEIRO, L. C...; LAGO, L. C. do. Restructuring in Large Brazilian Cities: The Centre/Periphery Model. International Journal of Urban and Regional Research, v. 19, n. 3, p. 369-382, 1995. 
40. RIBEIRO, L. C.; LAGO, L. C. do. O espaço social das grandes metrópoles brasileiras: Rio de Janeiro e Belo Horizonte. Revista Brasileira de Estudos Urbanos e Regionais, n. 3, 2000.

41. RIBEIRO, L. C. et alli. Desigualdades Urbanas. Desigualdades Escolares. Rio de Janeiro: Letra Capital/ Observatório das Metrópoles, 2010. Disponível em: $<$ http://web.observatoriodasmetropoles.net/index.php?option=com_abook\&vie $\mathrm{w}=$ book \&catid $=1 \% 3$ Alivros $\& \mathrm{id}=89 \% 3$ Adesigualdades-urbanas-desigualdadesescolares\&ltemid =123\&lang $=$ pt $>$. Acesso em: 14 jan. 2016.

42. RIBEIRO, L. C.; KAZTMAN, Ruben. A Cidade contra a Escola. Segregação Urbana e desigualdades educacionais em grandes cidades da América Latina. Rio de Janeiro: Letra Capital/Observatório das Metrópoles, 2008. Disponível em:http://web.observatoriodasmetropoles.net/index.php?option =com_ab ook \&view $=$ book \& catid $=1 \% 3$ Alivros $\& i d=87 \% 3 \mathrm{Aa}$-cidade-contra-aescola\&ltemid $=123 \&$ lang $=p t>$. Acesso em: 14 jan. 2016.

43. RIBEIRO, L. C.; RIBEIRO, M. G. Análise Social do Território: metodologia para o estudo da estrutura urbana brasileira. Rio de Janeiro: Letra Capital/Observatório das Metrópoles, 2013. Disponível em: < http://web.observatoriodasmetropoles.net/index.php?option $=$ com_abook\&view $=$ book\&catid $=1 \% 3 \mathrm{Alivro}$ $\mathrm{s} \& \mathrm{id}=133 \% 3$ Aanalise-social-do-territorio\&ltemid=123\&lang=pt $>$. Acesso em: 14 jan. 2016.

44. RIBEIRO, L. C.; RIBEIRO, M. G. Segregação residencial: padrões e evolução. IN: RIBEIRO, L. C. (Org.). Rio de Janeiro: Transformações na Ordem Urbana. Rio de Janeiro: Letra Capital, 2015. p. 163-192. Disponível em: <http://transformacoes.observatoriodasmetropoles.net/livro/rio-de-janeiro/> . Acesso em: 14 jan. 2016.

45. RIBEIRO, L. C.; SANTOS JUNIOR, O. A. dos. Associativismo e Participação Popular. Rio de Janeiro. Observatório de Políticas Urbanas e Gestão Municipal/ IPPUR/FASE, 1996. Disponível em: < http://web.observatoriodasmetropoles.net/ index.php? option $=$ com_abook $\&$ view $=$ book $\&$ catid $=1 \% 3$ Alivros $\&$ id $=64 \% 3$ Aass ociativismo-e-participacao-popular\&Itemid=123\&lang=pt $>$. Acesso em 14 jan. 2016.

46. RIBEIRO, M. G. Educação, Posição de Classe e Território. Uma análise das desigualdades de renda em regiões metropolitanas do Brasil. 2012. Tese (Doutorado em Planejamento Urbano e Regional) - Instituto de Pesquisa e Planejamento Urbano e Regional, Universidade Federal do Rio de Janeiro, Rio de Janeiro.

47. RIBEIRO, L. C.; RODRIGUES, J. M.; CORRÊA, F. S. Território e Emprego: segregação, segmentação urbanas e oportunidades ocupacionais na Região Metropolitana do Rio de Janeiro. Anais do XVI Encontro Nacional de Estudos Populacionais. Caxambu-MG: ABEP, 2008. 
48. RIBEIRO, L. C., SILVA, E. T., RODRIGUES, J. M. Metrópoles Brasileiras: diversificação, concentração e dispersão. Revista Paranaense de Desenvolvimento, número 120, pp. 171-201, Jan/Jul 2011.

49. SANTOS, C.; BRONSTEIN, O. Meta-urbanização: o caso do Rio de Janeiro. Revista de Administração Municipal, Rio de Janeiro, v. 25, n. 149, p. 6-34, 1978.

50. SANTOS JUNIOR, O. A. Governança empreendedorista: a modernização neoliberal. IN: RIBEIRO, L. C. (org.). Rio de Janeiro: Transformações na Ordem Urbana. Rio de Janeiro: Letra Capital, 2015. p. 453-483.Disponível em: <http:// transformacoes.observatoriodasmetropoles.net/livro/rio-de-janeiro/> . Acesso em: 14 jan. 2016.

51. SINGER, P. Economia Política da Urbanização. São Paulo: Brasiliense, 1975.

52. SILVA, R. Indústria e desenvolvimento regional no Rio de Janeiro: 19902008. Rio de Janeiro: Editora Fundação Getúlio Vargas, 2012.

53. SOBRAL, B. L.. Metrópole do Rio e projeto nacional. Uma estratégia de desenvolvimento a partir de complexos e centralidades no território. Rio de Janeiro: Garamond, 2013.

54. SOUZA, J. A Gramática social da desigualdade brasileira. Revista Brasileira de Ciências Sociais, 19, número 54, fevereiro de 2004.

55. TAVARES, M. da C. Império, território e dinheiro. In: FIORI, J. L. (Org.). Estados e moedas no desenvolvimento das nações. Petrópolis: Vozes, 1999.

56. VETTER, D. The Distribution of Money and Real Income in Grande Rio's Metropolitan System. Los Angeles: UCLA, 1975.

57. VETTER, D. et alli. Apropriação dos benefícios das ações do Estado em áreas urbanas: seus determinantes e análise através da ecologia fatorial. Revista Brasileira de Geografia, Rio de Janeiro, ano 43, n. 4, p. 457-477, out./dez. 1981. 58. VETTER, D. et alli. A apropriação dos benefícios das ações do Estado em áreas urbanas: seus determinantes e análise através de ecologia fatorial. Revista Espaço e Debates, n. 4, p. 5-37, 1981.

Recebido em: 12/01/2016 Aceite final em: 15/04/2016 